\title{
In search of design principles for developing digital learning and performance support for a student design task
}

Lars Bollen, Hans van der Meij, Henny Leemkuil

University of Twente

\author{
Susan McKenney \\ University of Twente \\ Open University of the Netherlands
}

\begin{abstract}
A digital learning and performance support environment for university student design tasks was developed. We describe the design rationale, process, and the usage results to arrive at a core set of design principles for the construction of such an environment and present a collection of organisational, technical, and course-related requirements that led to the particular setup of the targeted environment. Building upon the established learning management system Moodle, we designed a backbone structure that fitted onto the analysis, synthesis, construction, and evaluation intervention model. Within these four phases, students were able to find activity checklists, tools, and information to support their design activities. The environment was supplemented with tools for group communication and collaborative report writing. It has been used for 5 weeks by 35 students who worked in groups on a design task. We analysed the students' appraisals for usability and examined usage data from their action logs. Results indicate that students were positive about the environment and generally used its facilities frequently. The discussion revolves around the issue of how to achieve a balance between constraints, freedom, and scaffolding. A set of design principles is proposed for the construction of future versions of a learning and performance support environment.
\end{abstract}

\section{Introduction}

The University of Twente, founded in 1961, was originally a purely technical university. Students could earn an engineering degree in electrical, mechanical, or chemical engineering. The university broadened its educational horizon in the mid-1970s when it opened a faculty for the social sciences. In the year 2002, a psychology department enriched this faculty. Recently, the Board of Directors of the university gave the stimulus for an important renovation of the curriculum for the bachelor programs in all faculties. This led to a uniform roster that better facilitated students to choose from the courses offered throughout the university. A second major change was that the engineering approach would be the pivotal point for the didactic approach in the new curriculum in all faculties. In each semester, a set of modules was offered, each presenting a combination of theory, skills training, and design tasks. In a design task, students work in teams to construct a solution for a real or realistic problem. The realisation of that solution would be supported by a digital environment. This paper discusses the development of that environment (called TOM: Twents Onderwijsmodel, English: Twente Educational Model, an acronym generated from the name of the university's new educational program) for second-year psychology students.

This paper offers an example of the design and construction phase of design research (McKenney \& Reeves, 2012). This phase involves rational, purposeful consideration of knowledge and concepts that can be used to address specific problems in practice. As potential solutions are generated and explored, the underlying theoretical and practical rationales are elaborated. This allows the design framework to be evaluated and critiqued. The paper describes a framework for supporting student learning by design (LBD), along with its theoretical and empirical grounding. The leading questions in this paper are (1) What are the design principles for building a digital learning and performance support environment for a student design task? (2) What do usability findings tell us about the learning environment and its design principles? The approach we took to address these questions is that of developing the environment first, and then to reflect on what we did and why. The approach is also qualified as reflective practice (McKenney, 2008). According to Schoenfeld (1999), such an approach lies at the heart of design 
experiments; that is "Sometimes you have to build something to see if it will work. Without stopping let me add: and then you have to study the hell out of it. We don’t do nearly enough of that.” (p. 12).

The set-up of the paper follows the steps in the development process. Thus, it begins with a design rationale, and then progresses into the design requirements, actual design, testing, and reflection, at the end in which we advance a set of design principles. First, we introduce the three pillars of the LBD approach that provided the backbone for the design of our learning and performance support environment. Thereafter, we describe the organisational, technical, and course requirements for the environment. Next, we describe the course module as a whole and the place of the student design task. Thereafter, we describe its actual design and report on the usability outcomes that were obtained from action logs and student appraisals of the environment. We conclude by advancing a set of design principles and we discuss the opinion that a learning and performance support environment must find a balance between constraints, freedom, and scaffolding.

Educational design research is undertaken to achieve the twin goals of yielding both practical and scientific outcomes. In this study, the design principles and examples given constitute a practical contribution for those interested in designing similar modules for use in higher education. The theoretical contribution of the paper is explorative (not confirmatory) and takes the form of new hypotheses based on the design and evaluation experiences described.

\section{Grounding the initial design}

The design researchers creating the new course module (also the authors of this paper) have been teaching courses about design to the target group and using an LBD approach for many years. Also, the time available for design work did not allow for a formal needs and context analysis phase. Therefore, the design researchers relied on their existing knowledge about the broader module structure and the target group as well as recent literature to shape the initial design. This section describes four key sets of ideas underpinning the initial design: context, student needs, LBD, and usability.

\section{Context}

The broader context for TOM is the module "Psychology in Learning and Instruction," which is taught in the first semester of the second year of the bachelor course "Psychology". This module (15 European credits, EC, comprising a total of 420 study hours) consists of three parts:

- Theoretical part about learning and instruction (“Theory”- 5 EC)

- Methods and techniques part (“Skills lab” - 5 EC)

- Design and evaluation part (“Design task”- 5 EC).

The parts were scheduled in sequential order. In the theory part, students develop an initial understanding of how people learn and how instruction can promote the learning process while taking into account individual differences in age, cognitive development, and motivation as well as prevalent learning deficiencies such as dyslexia and dyscalculia. This theoretical knowledge is brought to life in the skills lab where students prepare and deliver mini-lessons to their peers and investigate the learning activities and learning outcomes in the lessons given by their peers. Armed with their theoretical and practical background and experience, students start their design task in which they design an instructional intervention.

More specifically, the students are asked to construct an interactive learning environment about nutrition (e.g., healthy food, weight problems, a good energy balance). Students follow their own interests, more or less, with regard to (a) the specific topic they wanted to aim for, (b) the kind of intervention they planned to design, and (c) the intended audience for the intervention. To complete the design task, students must follow the four steps in the design cycle described by the analysis, synthesis, construction, and evaluation (ASCE) model (Wiering, Pieters, \& Boer, 2011). The design and evaluation phases are especially considered to encourage students to apply previously acquired knowledge as they work on the authentic problem. 
In the 5 weeks in which the student design task ran, a project room was reserved each week for two voluntary 2-hour sessions. Groups could meet each other during these sessions and exchange ideas. In addition, the teacher was always present for consultation and advice. In the final, obligatory session, each group had to present its prototype and hand in their report. The learning goals of the design task were the following:

- Formulate learning goals and make reasoned choices for instructional design theories to reach these goals.

- Transform goals and theories systematically into a design and prototype of an interactive learning environment.

- $\quad$ Perform and report on a small formative evaluation of the prototype.

- Cope with the difficulties in the management of, and communication within, a cooperative design task.

\section{Student needs}

Students were in the first semester of the second year. In the first year, they already had experience with the new curriculum and with design tasks. The tasks in the first year of the psychology curriculum, however, were heavily structured. Students got a lot of support and feedback from their tutor during the design process. In the second year, they had more freedom, and the tasks were more open. Students appreciated this but they also indicate that they would have liked some guidelines and tools to support their design process.

Thirty-five students (28 females and 7 males) participated in the design task. Students worked in selfformed groups. There were six groups of 4 students (A, B, C, G, H, and I), and three groups of 3 students (D, E, and J). One group consisted of 2 students (F).

\section{LBD}

Current approaches to teaching and learning generally tend to be characterised by three aspects: (a) activity, (b) task authenticity, and (c) technology. Students should be actively engaged in problem-solving activities, meaning mental engagement with the subject matter, which has since long been considered vital for learning (Wittrock, 1974). Mayer (2008) has elaborated on this view by proposing a distinction between three activity types, namely selection, organisation, and integration. Each activity type refers to a particular phase in information processing. Selection concerns the first phase in which information must be selectively attended to. Organisation refers to mentally constructing a coherent structuring of the information. In integration, students must connect the new information to the prior knowledge they already have on the topic.

In addition to emphasising activity, students should also become more engaged in solving real or realistic tasks. The insight that students need more practice in solving realistic problems emerged as a reaction to the finding that students' knowledge too often remains inert. Students find it hard to apply what they have learned in school in their jobs. This finding provided an important stimulus for the rise of the constructivist approach in education (Bransford, Brown, \& Cocking, 2000; Resnick, 1987).

The third aspect in current educational approaches is the functional integration of technology (Spector, Merrill, van Merrienboer, \& Driscoll, 2008; van der Meij, 2012). Technology use in education has always been a heavily debated issue. Each time a new tool (e.g., radio, television, computer) becomes available, expectations rise that it will revolutionise education. It never does. An important reason is that technology is a means rather than a goal. Technology should be employed because it can serve an important role in achieving the objective(s) of a lesson or series of lessons.

An approach in which these three aspects have emerged is LBD. LBD is an activity-centred approach. Student activities should be geared towards the goal of creating a design solution. The type of scientific processes that LBD emulates is that of an engineering approach. Students must engage in a systematic and scientific process of problem-solving that (repeatedly) involves engagement in the processes of selection, organisation and integration. In addition, LBD requires students to apply fundamental or theoretical knowledge. In constructing a solution, students must find and use a theory to ground their 
designs. The design tasks in LBD are often real or realistic. The relevance of the design tasks should have immediate intuitive appeal. Carroll's approach to teaching Smalltalk programming (see van der Meij \& Carroll, 1998) can serve to illustrate what this requires of the designer of LBD. Instead of asking informatics students to learn lots of basic programming codes, Carroll presented his students with the design problem to fix a rigged blackjack game. In addition to being a highly motivating task, the design problem also confronted students with key issues of programming in Smalltalk. Technology often serves a supportive role in LBD. For instance, students may be offered a repository of articles and books to speed up their search for pertinent literature. Also, tools are sometimes made available for students to test design solutions.

The presumed benefits of LBD are threefold (compare Du Plessis \& Webb, 2011; Janssen \& Waarlo, 2010; Vreeman-de Olde, de Jong, \& Gijlers, 2013):

- $\quad$ Students develop the core competencies of designers. A systematic, iterative approach plays a prominent role as a methodological component in this development.

- Students are motivated towards what they need to achieve. Their motivation is increased by the fact that the design task they must tackle is tangible and relevant.

- Students learn to apply knowledge from basic theories. They must translate theoretical knowledge into principles for design that, in turn, must yield design solutions.

\section{Usability}

No matter how well considered the construction of a module, there can be no substitute for measuring what users actually do, think, or feel as they interact with it (see Schriver, 1997). In other words, the user should be considered a major stakeholder in design and evaluation. As described above, the (presumed) needs of the students of the module provided input for its construction. For the evaluation of the module, usability testing was applied, where the leading question was how well a design actually works, and which improvements can be done concurrently and/or retrospectively.

In concurrent testing, information is gathered in real time. A typical example is the think-aloud method in which users are asked to verbalise what they are thinking while doing. The method that we chose to gather real-time information was user logs. Compared to think-aloud protocols, user logs have the important advantage that they are unobtrusive and that they can quickly and easily provide accurate information on what students do. User logs can be explored to discover new or unforeseen usage or they can be searched for data that can address a specific research question. In this study, befitting the focus on supporting learning by doing, user logs were searched for information about the frequency of tool usage.

In retrospective testing, the user is asked to look back and reflect on what has occurred. Such reflections are typically measured with a questionnaire, interview, critical incident approach, or a comprehension test. In view of the limited time for testing (both from the designers and students), a questionnaire approach was selected to gather information about what the students think or feel about TOM. The questionnaire focused on the three critical aspects of usability distinguished in a famous publication by Bethke and her colleagues at IBM (Bethke, Dean, Kaiser, Ort, \& Pessin, 1981). According to that study, people find information easy to use when it is (a) easy to find, (b) easy to understand, and (c) tasksufficient. The first aspect refers to accessibility. TOM students should have little trouble locating the information they are looking for. The second aspect addresses the issue of comprehensibility. Usability is at risk when students cannot quickly grasp the meaning of an article, book, or tool. Finally, task sufficiency refers to presenting information and tools that are relevant and sufficient for the task at hand. All essential information needed to do the task should be included.

\section{Design requirements}

The design of a digital environment for the student design task should fit the LBD approach that we adopted. Our foremost design consideration for this construction concerned the choice for a methodology that could scaffold the students' systematic and scientific process of design. The obvious candidate for this selection was the ASCE model. The ASCE model concentrates on psychological interventions (Wiering et al., 2011). It was introduced to the psychology students in their first year, and students are still regularly reminded of that model in classes in their second year. 
As mentioned above, the ASCE model distinguishes four core design phases or steps: analysis, synthesis, construction, and evaluation. It resembles the method for problem-solving described by Polya (1945), who discerned four phases: understanding the problem, devise a plan, carry out the plan, and looking back. Analysis comprises the analysis and definition of the problem. Synthesis refers to deciding on the behavioural determinants and to selecting matching methods and strategies for behaviour change (the intervention). Construction refers to the concrete program or product, and how that product is used in actual practice. Evaluation focuses on the assessment of the impact of the intervention. The main question in evaluation is whether the desired behaviour occurs and learning has taken place. This phase also comprises a process evaluation. For other, non-psychological intervention tasks, similar phases have been described more recently by Jonassen (1997) and Carlson and Bloom (2005).

Each phase consists of several activities that should be performed in sequence (and possibly iteratively). For instance, during analysis students should first engage in an exploration of the design task and the conditions in which it occurs. Generally, students should therefore ask questions such as "What is the problem?”, "When does the problem occur?”, "How prevalent is the problem?”, and "How serious is the problem?” This should then be followed by a deliberation (e.g., brainstorming, drawing a concept map) on the intervention objective and a as means of measuring its accomplishment.

\section{Course requirements}

The presentation of the ASCE model in TOM should serve several functions, all of which concern the course itself. First, it should remind students of the ASCE model as the leading framework and should give a succinct description of the main input and output expected from each phase. It should enable students to easily perform checks on the execution of their actions in each phase and include tools to facilitate certain activities. These considerations led to the following set of course requirements (CR):

- $\quad$ CR1. The system should present the ASCE model and make a distinction between its four phases.

- $\quad$ CR2. The system should contain a checklist with the activities for each phase.

- $\quad$ CR3. The system should contain tools that support the different activities in each phase.

- CR4. The system should contain relevant background information related to the phases/activities.

\section{Organisational requirements}

The organisation of the design task led to another set of considerations. One factor concerned teamwork. Real design projects are often conducted in multidisciplinary teams, where not only does the collaboration bring different kinds of expertise into the design, but also the conversations among the team members stimulate the articulation and discussion of design options (see Jonassen \& Rohrer-Murphy, 1999). In TOM, students had to work in teams of 2 to 6 . In addition, the design activities of individual members should be coordinated and should result in a single design solution for the group. For this reason, TOM should offer communication support.

Students nowadays have lots of different ways of communicating with each other, so why integrate communication in TOM? One reason is to offer students a single environment in which they could do all they needed to do for their design task. We considered that constructing an all-inclusive environment would facilitate communications across groups. For instance, it was deemed to come in handy for sharing when a group has found an interesting new application or pertinent information that is relevant for all groups.

Another factor was the consideration that a communication section should also serve the teacher in the course. In his/her role as counsellor (to give specific advice on a group's current design approach) or as a supervisor (to intervene in a group's collaboration or planning if necessary), it was considered desirable that the teacher could (re)view the existing group communication and could self-initiate an interaction with a group or a member of a group.

Finally, an important organisational requirement was for all groups to hand in a single report describing their design process and illustrating their product. For reporting, the same consideration of allinclusiveness was followed. That is, the students should easily be able to copy/paste sections of what they 
had communicated or built in TOM into their report. In addition, it should be easy for them to merge contributions of individual team members into a group report. Thus, the following set of organisational requirements (OR) was drafted:

- OR1. The system should facilitate communication between all course members.

- OR2. The system should facilitate information, file (and link) sharing between all course members.

- OR3. Each group should have a specific group space that is only accessible to the group members and their tutor.

- $\quad$ OR4. The system should facilitate communication between subgroup members.

- OR5. The system should facilitate file (and link) sharing between subgroup members.

- $\quad$ OR6. The system should facilitate collaborative report writing between subgroup members.

\section{Technical requirements}

The technical requirements identify and describe a set of features and characteristics that the learning and performance support system needs to fulfil from a technical perspective to create a maintainable, flexible, and usable system.

For reasons of grading and the assignment of credit points, the system needs to be able to authenticate against the university's student account system. The identity of the user needs to be clear and unambiguous. Ideally, existing authentication mechanisms can be used for this purpose. Also, with the increasing availability and usage of mobile devices such as smartphones, iPads, and tablets in everyday life, the system need to support these devices with respect to varying screen sizes and alternative input modalities. Because students are expected to carry out a considerable part of their work in various places outside the classroom (e.g., at home, in the library, while commuting), it was considered important to address these by applying responsive design principles (Gardner, 2011). That is, the visual layout, available features, and input methods had to adapt to the devices used.

In addition to the distribution of learning resources and information, the system also had to support the integration of interactive applications as activities in the various phases. This integration needs to be as seamless as possible to improve the user experience and to reduce media breaks. Examples for interactive applications are concept mapping tools, collaborative writing tools (including wikis), and design prototype building tools. The use of web-based technologies (e.g., browser-based applications using JavaScript, HTML5) allows an easy integration of various applications in one common environment. As a consequence of the requirements concerning group work and communication, the envisaged environment needed to support the creation and administration of student groups. This led to the following set of technical requirements (TR):

- $\quad$ TR1. The system needs to authenticate users against the university's student register.

- TR2. The system needs to support mobile devices and needs to follow responsive web design principles.

- $\quad$ TR3. The system needs to allow the integration of interactive applications.

- TR4. The system needs to support the creation and administration of student groups.

\section{TOM structure}

Following the course and organisational requirements, TOM has been structured into a common introductory part for general course information, and a core part with the sections Communication, Product and Process, and Report, in which the major information and tools for achieving the design task were given (see Figure 1). This structure is shown in Table 1. Because the introductory part is common in many learning management systems (LMSs), we will not elaborate its design and usage. 
Table 1

Structure for TOM

\begin{tabular}{|c|c|c|c|}
\hline $\begin{array}{l}\text { Common for all } \\
\text { students and } \\
\text { teachers }\end{array}$ & & Introduction, information, and general topics & \\
\hline \multirow{2}{*}{$\begin{array}{l}\text { One instance } \\
\text { (copy) per student } \\
\text { group }\end{array}$} & \multirow[b]{2}{*}{ Communication } & Product and Process & \multirow[b]{2}{*}{ Report } \\
\hline & & Synthesis Construction & \\
\hline
\end{tabular}

The three sections, Communication, Product and Process, and Report, each receive their own place and visual presentation in TOM. Also, a brief, one- or two-sentence description explains the content covered by each section.

The Product and Process section, which stands at the centre of the structure, was further subdivided into the four steps of the ASCE model (CR1). Furthermore, within each step information was presented about (a) goals and activities, (b) tools, and (c) background information (CR2, CR3, CR4; see Figure 2). These components have been formatted following an information mapping approach (Horn, 1993); that is, each component had the same visual design and fixed position throughout TOM to facilitate navigation and access. This section was designed to support the students' core task - to design a psychological intervention in the area of health education.

The Communication section presents four technical means for communication - to discuss; to exchange ideas and comments; to share files; or to create link collections (see Figure 1). Although communication between project group members is expected and important throughout all activities in TOM, it has been decided to make this a distinct section to prevent fragmentation of communication activities and to ease transfer and integration of communication results. As a side effect, the use of communication tools in (online) group activities can foster collaborative learning skills (Khalil \& Ebner, 2013). The use of this section was not obligatory, but it served as an overall support to enhance the group collaboration. Students did not receive instructions on how they are expected to use this section; the use of the Communication section was completely optional.

Similar arguments hold for the Report section (see Figure 1). Here, two different collaborative writing tools and a plain "upload report" option were provided. Writing the design task report relates to all subactivities; particularly it collects results from the Analysis, Synthesis, Construction and Evaluation subsections, and to this end an overarching, separate Report section has been added. This section reflects the students' final task - to write and hand in a report on their process and results from their core task. Similar to the Communication section, the use of this section was non-obligatory; students were allowed to use any word processor and could hand in their report via email. 


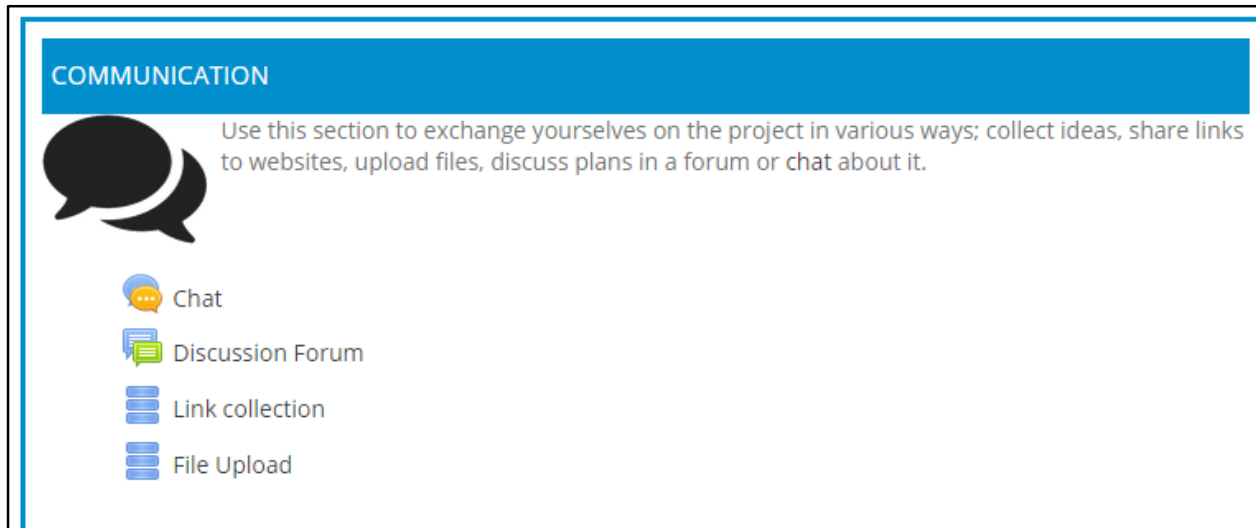

PRODUCT AND PROCESS

The following sections support the creation of the actual product. Since the different project products will be unique in their nature, work processes and outcome, the kind of support (e.g. which tools and resources can help) is also unique and will unfold during the course. The phases in the design process are based on the ASCE model for intervention design.

ANALYSIS

SYNTHESIS

CONSTRUCTION

EVALUATION

This subsection helps to create the final report. During the project, a wiki can be used to

collaboratively write a report and finally submit it.

2

$\longrightarrow$
W Draft report wiki
D. Collaborative report writing
Specific for Project Demo
Upload your final report

Figure 1. The overall TOM structure with the Communication, Product and Process, and Report sections 


\section{ANALYSIS$$
{ }_{\mathrm{R}}^{\mathrm{S}} \mathrm{C}_{\mathrm{c}}^{\mathrm{s}}
$$ \\ Goals and Activities \\ Goals of this phase \\ Description of activities in analysis phase \\ Tools \\ Concept mapping tool}

A concept map is a visual representation of your thoughts, information and knowledge. A concept map contains concepts and relationships between these concepts that are visually represented by means of arrows and colours. This helps you organize information and provides a structure that makes you come up with new ideas more easily.

Stoodle shared whiteboard

Through Stoodle you can quickly create a collaborative whiteboard space. On your whiteboard you can type, draw, and upload images. You can connect Stoodle to your computer's microphone and talk your collaborators while drawing, typing, or sharing images.

Stoodle does not require you to create an account. To create a Stoodle whiteboard space just click "launch a classroom," name your room, and share the URL assigned to your room.

Web page annotation tool

Bounce is a lightweight application for giving quick feedback on a web page. You enter the URL you want to annotate, add your notes, and then share your feedback with anyone you want.

\section{Background Information}

Overview of instructional design theories

In the field of instructional design we often use models that are different from the ASCE model. An overview of instructional design theories (main ideas and references) can be found here.

\section{ADDIE model}

The ADDIE model is a framework that lists generic processes that instructional designers and training developers use.

Figure 2. The Analysis activity subsection with an overview of the main components: goals and activities, tools, and background information 


\section{LMS}

Following the technical requirements, a Moodle (version 2.7, see https://moodle.org) environment was chosen as the target environment for TOM. Among the many LMSs (e.g., ILIAS, see http://www.ilias.de; Sakai, see https://www.sakaiproject.org; or Blackboard, see http://www.blackboard.com), Moodle has the advantage that it is free and open source, and can draw on a large community of developers, teachers, and students. Moodle can also be easily installed in the local organisation's infrastructure, as it runs on standard server configurations. It addition, its plug-in-based architecture facilitates the usage of existing components along with the instalment of new, self-developed features. Another advantage is that the design and layout of the environment can be easily adapted and modified.

Moodle can authenticate users against an external lightweight directory access protocol (LDAP) server, which was supported by the university's infrastructure. This feature realised requirement TR1. Moodle developers have also recently increased support for mobile devices. They have introduced responsive web design, making it usable on devices like smartphones or tablets as well. Furthermore, native Android and iOS apps are available, for an even more tailored access to the environment. This feature realised requirement TR2.

With a default installation of Moodle, many interactive applications (so-called activities) are already available (e.g., a forum, file sharing, chat, quizzes, surveys, or a wiki). Plug-ins created by third-party developers are available as well, which increases the number of potential applications. In addition, it is possible to seamlessly integrate external (interactive) web pages and web applications, like an external concept mapping tool or Google Docs for synchronous editing of text documents. These features realised the requirements OR1, OR2, OR6, and TR3.

As a standard feature of many LMSs, Moodle supports the flexible creation and organisation of groups. Students can be assigned to courses, and student groups can be created flexibly to work on group assignments. These features, together with the course structure described above, allow teachers to establish communication with the whole group of students, with a sub-group of students, or with individuals, thus realising requirements OR3, OR4, OR5, and TR4.

In summary, Moodle already provides many features that are needed for the realisation of the given requirements, and its open source characteristic makes it an ideal candidate for necessary adaptations and extensions.

\section{Method for student evaluation of TOM}

To gather information about students' actions in TOM, all user actions were recorded with an extensive logging system. The action logs contain such information as who performed which action, at what time, from which IP address. Actions typically have the granularity of meaningful usage of TOM, such as logging into the system, sending a chat message, uploading a file, or clicking a link to an external resource. Table 2 presents two examples of the granularity and content of the action log information. The first row denotes a student action of creating a new forum discussion thread. The second row describes the action of opening an external resource. The actual action logs contain more information, such as course ID, access through browser or app, object identifiers. All in all, the data logs that were recorded in TOM consisted of 6896 student actions.

Table 2

\begin{tabular}{|c|c|c|c|c|c|c|}
\hline id & Event name & action & target & user id & time & $\ldots$ \\
\hline 11 & \mod_forum\discussion_created & created & discussion & 40 & 1414665404 & \\
\hline 13 & \mod_url\course_module_viewed & viewed & url & 23 & 1414054234 & $\ldots$ \\
\hline
\end{tabular}

Making use of the (technical) availability of tracking student activities provides opportunities for gaining insights into the actual usage of a (digital) learning platform, in contrast to, for example, knowledge gain tests or students' self-reported usage of a system. These techniques are not innovative by itself, and have been widely used in various approaches for many years, for example, for gaining information on the usability of systems (Hilbert \& Redmiles, 2000) or to help create intelligent tutoring systems (ITS) with 
the help of educational data mining techniques (Romero \& Ventura, 2007). Consistencies and/or mismatches between action log information and other observed information can help to better understand student activities and can lead to the redesign of aspects of the learning platform, as described in more detail in later sections.

\section{Granularity}

During the 5-week period that the design task ran, we regularly saw groups of students spread across the building to work on their assignment. In doing so, students frequently flocked around a single computer that was connected to TOM. This observation meant that an analysis of the action logs of individual students would give a very inaccurate picture. Therefore, all further action log analyses concentrated on the merged findings of all group members, that is, the action logs of the single group members have been plainly concatenated for further analyses. Figure 3 gives an overview of the overall number of actions per group in TOM. The data show considerable variation. The numbers of actions range from a minimum of 2 (group J) to a maximum of 696 (group E), with an average value of $M=329.3(S D=202.5$ ).

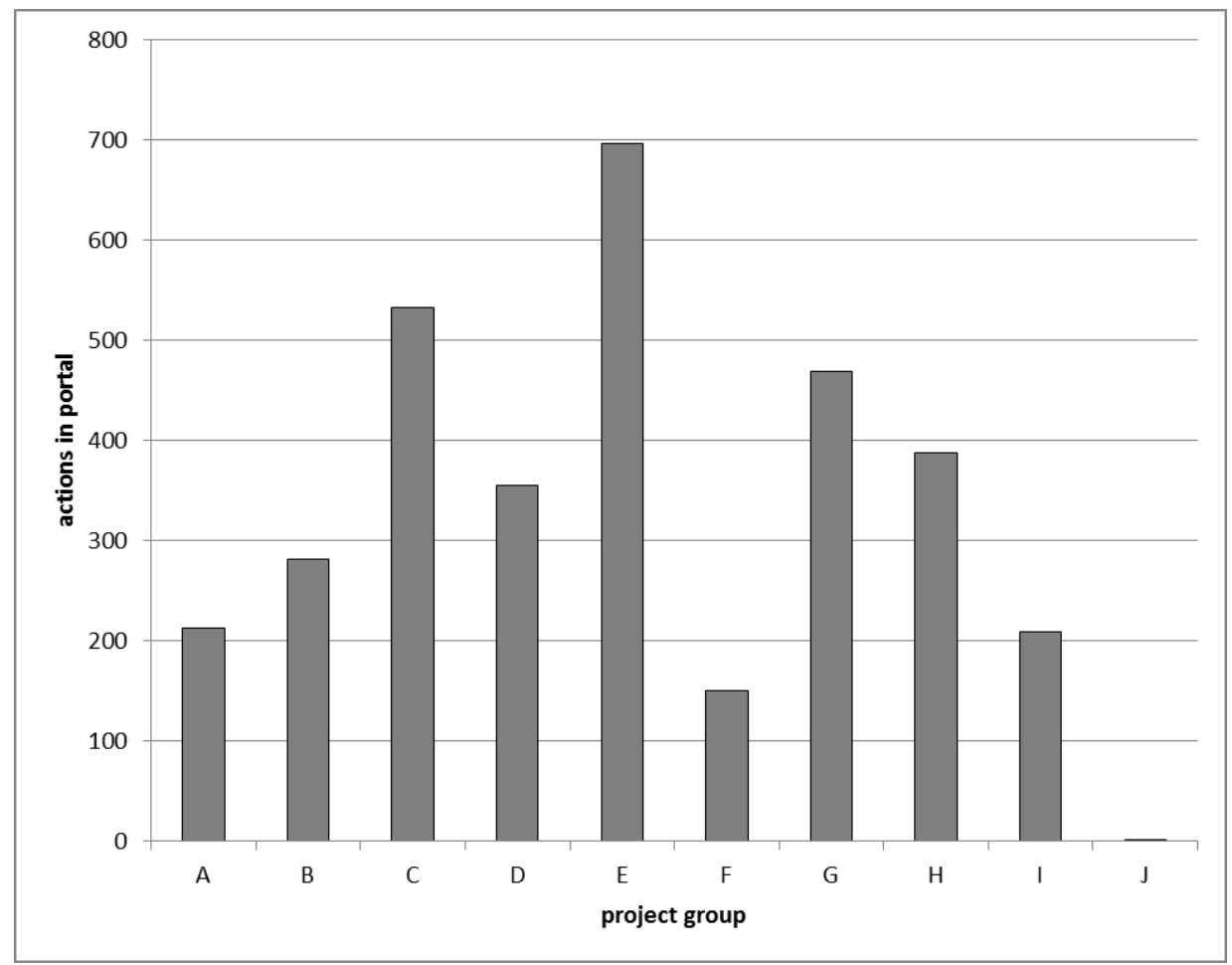

Figure 3. Number of actions of each group (A through J)

\section{Location and active hours of TOM usage}

The recorded IP address of the device used to access TOM gives some insights into the location from which the student gained access. Out of a total of 4201 actions, about $61 \%$ have been performed from within the campus network, whereas 2695 actions (about 39\%) originated outside the campus. These numbers have to be read with some caution, however, because students living on campus and students accessing TOM through a VPN connection were both counted as access from within the campus network.

Another impression of the students' work context, that is, their most active hours, can be gained from the distribution of actions over the daytime, as presented in Figure 4. It shows that most actions, about 89\%, have been conducted between 8 a.m. and 8 p.m., with a peak of 1149 actions between 9 a.m. and 10 a.m. The lowest value with 9 actions lies between 5 a.m. and 6 a.m. The peaks between 9 a.m. and 11 a.m. fit with the classroom sessions in the course. 


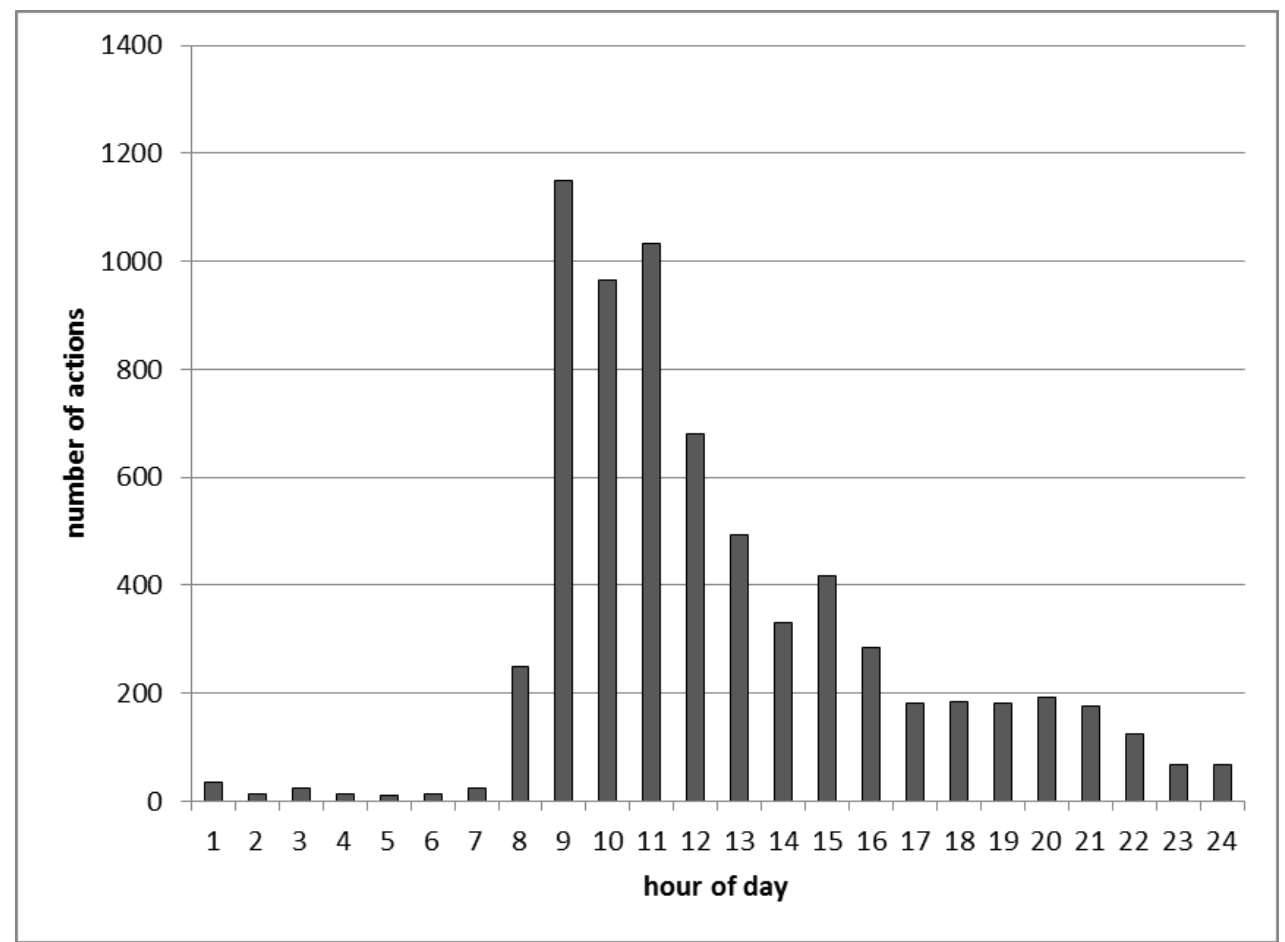

Figure 4. Distributions of actions over the day

To assess students' opinions about TOM, a short, one-page paper usability questionnaire was designed. For TOM as a whole, as well as for each of the three sections (i.e., Communication, Product and Process, and Report), the questionnaire asked the three core questions posed by Bethke et al. (1981), namely whether:

(1) information was easy to find

(2) tools were easy to use

(3) tools were useful.

Students could indicate their level of agreement with each question on a 7-point Likert scale, with the number 1 representing total disagreement, and the number 7 representing total agreement. After the 12 closed questions, an open question was posed as to whether students had any special likes or dislikes that they wanted to tell us about. The answers to these open questions were grouped into categories and tallied for frequency. The questionnaire was administered at the close of the last session, after the students had presented their prototype and handed in their report. Thirty-one students filled in the questionnaire.

\section{Results}

\section{Actions in and opinions on TOM as a whole}

Figure 5 shows the distribution of actions per group in the three sections, Communication, Product and Process, and Report. For many groups (A, C, E, G, H, and I), usage of the communication tools produced most of the actions in TOM. Some groups (B, D, and F) used these tools less frequently. The predominant usage data in these groups came from the Product and Process section. In line with the data presented in Figure 3, group $\mathrm{J}$ did not use TOM at all. (The two actions from group $\mathrm{J}$ as reported in Figure 3 originate from accessing the platform, but no material or tool has been used.)

Table 3 shows the outcomes of the students' overall appraisal of TOM as a learning environment. The average scores for the environment were just above the median of the scale. The high value of the standard deviation indicates that there is a large variety in students' opinions, especially about its usefulness. 
Table 3

Students' opinions* on TOM as a whole

\begin{tabular}{lc}
\hline \multicolumn{1}{c}{ Statement } & Mean (standard deviation) \\
\hline Information was easy to find $(N=31)$ & $4.45(1.59)$ \\
The environment was easy to use $(N=31)$ & $4.61(1.17)$ \\
The environment was useful $(N=31)$ & $4.52(1.88)$ \\
\hline *The scale values range from 1 to 7 (with $7=$ most positive); 4 = median value
\end{tabular}

*The scale values range from 1 to 7 (with 7 = most positive); 4 = median value

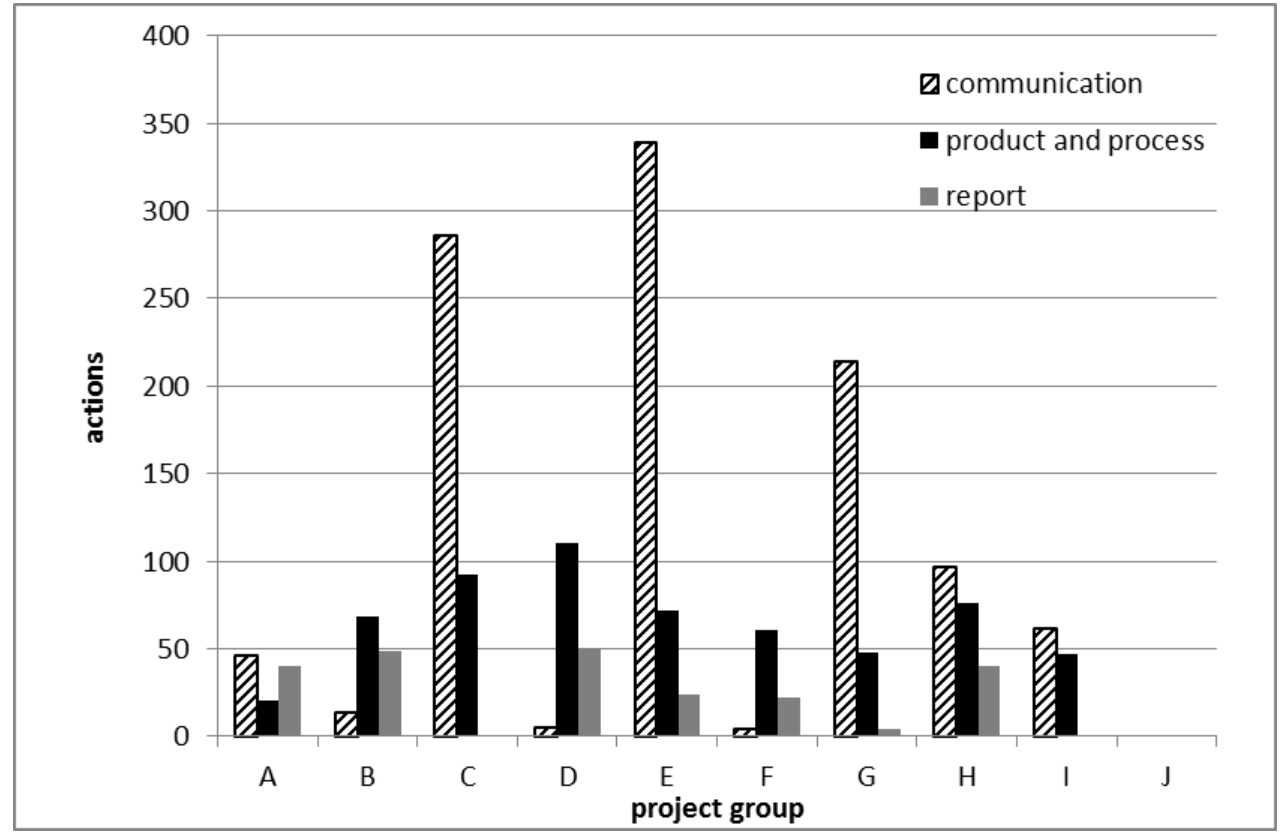

Figure 5. Actions in TOM sections Communication, Product and Process, and Report per group

The answers to the open question revealed that students were positive about the all-inclusive nature of TOM. They liked that everything they needed for their design task was available in one place. In addition, they mentioned that TOM provided them with useful references. Some students stated that they had not used the communication and reporting tools in TOM a lot because of other alternatives, preferring instead tools such as WhatsApp and Facebook for communication and Google Drive for reporting. Another reason for low usage of these tools was that communication and reporting were already reasonably well supported by the voluntary sessions in which they met face-to-face with their team members. Some students expressed technical objections, stating that they didn't like the tools to open in a window inside the environment because they couldn't resize the window.

While likes were also frequently expressed for the Description of activities in a phase subsection (see Figure 2), this section was not considered ideal. The activities description constituted a checklist. The checklist was designed as an authentic job aid by offering a comprehensive list of potential issues that could be of relevance to most design tasks.

Prioritisation of tasks was not included in the description, as this was expected to be discussed and decided by the students themselves. However, instead, this lead to a slight disarray and little usage of the proposed tools. Further, some students indicated that they would have appreciated a demonstration of the tools in earlier design task meetings, as well as a better linkage to the activities (rather than just the phase) they supported. Had we done so, perhaps it would have increased usefulness and ease of use, while also affording the opportunity to explain to students the importance of developing and exercising their own judgement (regarding which tasks are essential or not) to serve specific design challenges.

\section{Actions in and opinions on Communication in TOM}


The actions of each group in the Communication section are shown in Figure 6. The figure also shows the usage of the various tools that are available in this section of TOM (i.e., chat, forum, link collection, and file upload). The values range from 0 actions (e.g., chat actions in group A) to 308 actions for file upload in group E. It can further be seen that each communication tool has been used extensively by at least one group, and that not all groups used all tools. Groups E and G strongly favoured the use of the file upload tool, while group J did not use any communication tools at all. Group C used mainly the forum, while group A used the file upload and link collection tools almost equally. Group F is special in that it merely and incidentally used the link collection tool.

As an example, we compare the actions for the two groups with the highest usage count in this category in detail: group E, with 339 communication tools-related actions, 3 chat-related actions, 3 forum-related actions, 26 link collection-related actions, 307 file upload-related actions versus group C, with 286 communication tools-related actions, 5 chat-related actions, 270 forum-related actions, 4 link collectionrelated actions, 7 file upload-related actions. Although both groups have a comparable overall action count, the distribution of actions over the various communication tools differs considerably. While group E barely used the forum and made some use of the link collection tool and extensive use of the file upload tool, group $\mathrm{C}$ extensively used the forum above all other tools.

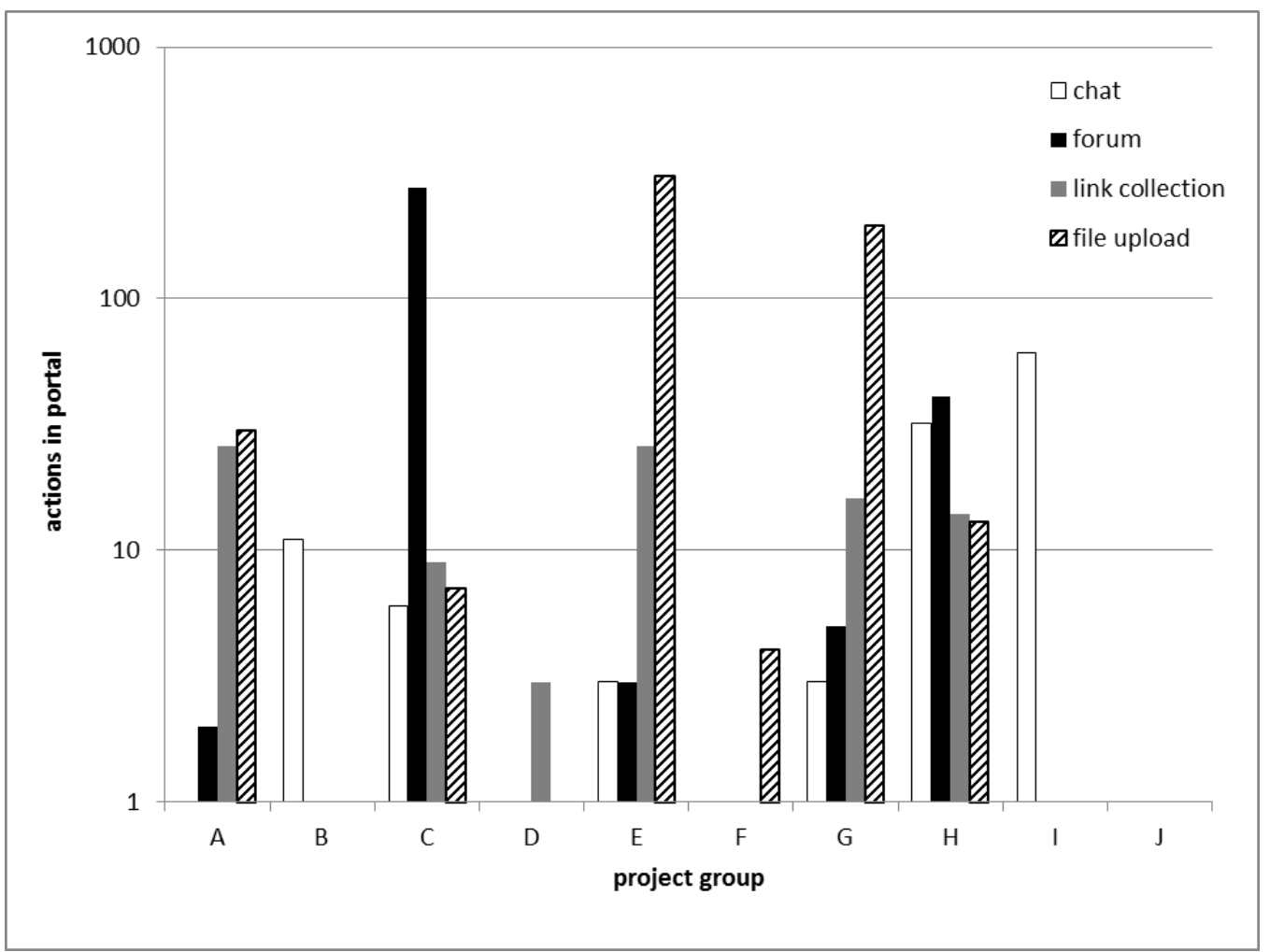

Figure 6. Actions per group for tools in the Communication section (Please note: The Y-axis is a logarithmic scale for better graph visualisation.)

Table 4 shows the outcomes of the questionnaire for the Communication section. The ratings of the students were all slightly above median value. In other words, they were neither very negative nor very positive about what the section had to offer.

Table 4

Students' opinions on Communication

\begin{tabular}{lc}
\multicolumn{1}{c}{ Statement } & Mean (standard deviation) \\
\hline Information was easy to find $(N=28)$ & $4.54(1.14)$ \\
The tools were easy to use $(N=28)$ & $4.89(1.20)$ \\
The tools were useful $(N=28)$ & $4.21(1.69)$ \\
\hline *The scale values range from 1 to 7 (with 7 = most positive); 4 = median value
\end{tabular}




\section{Actions in and opinions on Product and Process in TOM}

The Product and Process section supports students in their core activities for the design task. The information on goals and activities has been accessed most with a frequency of about 8 times on average per group $(M=7.6, S D=7.9)$. Beyond that, the usage data give a highly diverse picture. The average tool in the ASCE sections has barely been used $(M=1.3, S D=2.5)$. There are several probable causes for the underuse. One is that a high number of tools was made available, some of which serve the same goal in a slightly different way. Another reason is that some tools were simply not relevant for the kind of intervention that a group had decided to develop. We nevertheless kept these tools in the TOM environment to maintain consistency across groups. All in all, the usage data for this section suggest that there is a need for more guidance and scaffolding.

A repeated measures analysis comparing the three TOM sections showed a significant effect, $F(2,50)=$ 3.45, $p=0.040$. The mean scores for the Communication, Product and Process, and Report sections were 4.56, 4.95, and 4.21 respectively. Post hoc analyses (LSD statistic) revealed that the only significant difference was that between Product and Process and Report $(p=0.049)$. Table 5 shows the detailed outcomes of the student questionnaire. For all three usability questions, the ratings for this TOM section were higher than for the two other sections. A repeated measures analysis showed that there was a significant difference only for the factor easy to use, $F(2,50)=4.72, p=0.013$. Post hoc analyses again revealed that the appraisal for Product and Process differed from that of Report $(p=0.024)$.

Table 5

Students' opinions on Product and Process

\begin{tabular}{lc}
\multicolumn{1}{c}{ Statement } & Mean (standard deviation) \\
\hline Information was easy to find $(N=31)$ & $4.90(1.25)$ \\
The tools were easy to use $(N=31)$ & $5.10(1.19)$ \\
The tools were useful $(N=31)$ & $4.48(1.95)$ \\
\hline
\end{tabular}

*The scale values range from 1 to 7 (with 7 = most positive); 4 = median value

\section{Actions in and opinions on Reports in TOM}

The Report section supports students in writing their final report. It included three tools: (a) a wiki that afforded simultaneous editing by one person only, (b) a collaborative writing tool that was realised by embedding Google Docs, and (c) a simple file upload tool. The actions performed in the Report section are shown in Figure 7. This figure clearly reveals that usage of Google Docs $(M=21.1, S D=19.3)$ was highly preferred over usage of the wiki $(M=1.6, S D=4.1)$. The file upload tools have not been used at all. Three groups had a look at the upload tool, but finally decided to send their report by mail, which is a regularly used option in various courses at our university. 


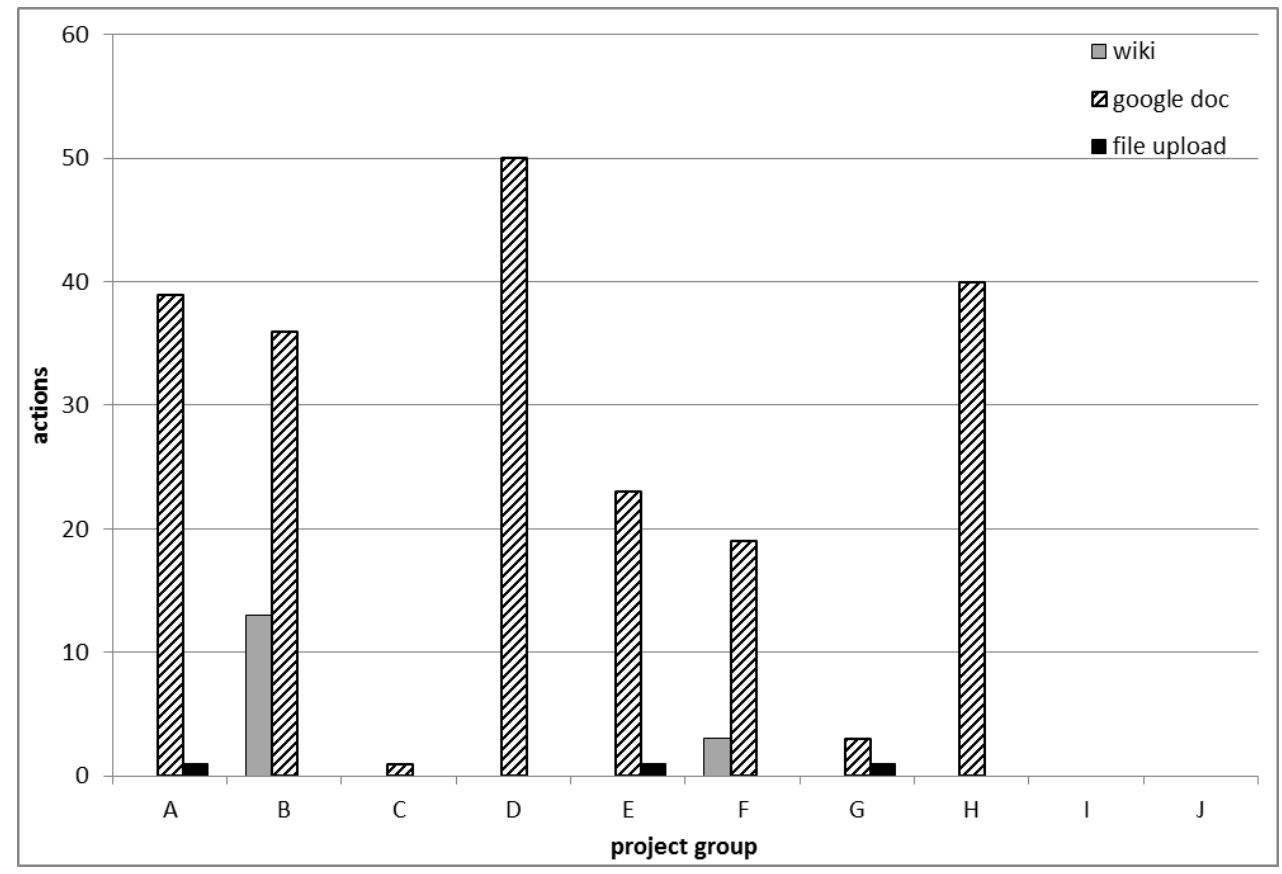

Figure 6. Actions per group for tools in the Report section

Table 6 shows the outcomes of the student questionnaire for Report. The ratings for Report were slightly above median value, but even less so than for Communication.

Table 6

Students' opinion on Report

\begin{tabular}{lc}
\multicolumn{1}{c}{ Statement } & Mean (standard deviation) \\
\hline Information was easy to find $(N=27)$ & $4.37(1.24)$ \\
The tools were easy to use $(N=27)$ & $4.22(1.34)$ \\
The tools were useful $(N=27)$ & $4.00(1.78)$ \\
\hline
\end{tabular}

*The scale values range from 1 to 7 (with $7=$ most positive); 4 = median value

\section{Discussion and conclusion}

This project was undertaken as design research, and not simply course development, to reach the twin goals of developing a theoretically and empirically robust TOM module while also producing outcomes that could serve the work of others engaged in similar activities. The TOM module was designed around understanding the broader educational context, user needs, LBD guidelines, and usability principles. The first round of testing focused on usability. This section summarises key findings, discusses their implications, and provides recommendations for future research.

The goal of the TOM module was to support groups working on a (psychological) design task. The overall usage of TOM, although not being compulsory, indicates that students showed a basic acceptance and motivation to use the system. Group J, who showed the least active participation in TOM, demonstrated an overall lack of motivation in the course and finished with a low grade. Group F also had a low activity score, but this group consisted of only two persons.

In the requirements and system design, we aimed at supporting mobile devices and responsive web design as well (TR2). However, in the usage statistics and final investigations, we did not focus on this aspect. How mobile devices and mobile learning scenarios can be meaningfully integrated in this approach by, say, making use of student response systems remains to be investigated in future studies (compare Bollen, Eimler, Jansen, \& Engler, 2012). The usage statistics of the tools in the category Communication (Figure 6) indicate that the different design groups and students follow different collaboration and communication preferences. Although students indicated that they used tools such as WhatsApp and Facebook to communicate, the various tools in TOM (i.e., chat, forum, link collection, file 
upload) have been used in different frequencies, and each tool seems to bring an added value to some students. Initially, we had reservations as to whether we should include the Communication section at all with so many other affordances for social and other exchanges. Looking back it seems we made the right choice here - the section did serve the students as they were working on their design task.

In the Product and Process section, the overview of activities was appreciated and consulted frequently. By and large, it justified the reason for its inclusion: as a job-performance aid affording an overview of activities and a check on their (possible) completion. The tools that were offered here were less frequently used. An important reason for this was that students were not acquainted with the tools. They had to find out how they worked and for which tasks and activities they might be useful. Students also reported that they found this took them too much time. This is in line with the findings of Edmunds, Thorpe and Conole (2012). They concluded:

Students also have clear requirements in terms of technology enabling them to produce more in the time that they have, and enabling them to be more effective. Technologies which do not meet these requirements may prove counterproductive or simply be ignored (p. 83).

What's striking is that the tool that is the most intuitive (the Padlet wall used for brainstorming) is used most often. Therefore, we recommend showcasing the tools in the first design task meetings and making a connection between the activity overview and the tools.

Our experiences and results from the Report section suggest that an easy- and intuitive-to-use collaborative writing tool is appreciated and used by students, while a more complex and not fully synchronised tool like Moodle's wiki tool (only one student was able to edit one page at a time) was barely used. This suggests including other collaborative, web-based production tools in future. Candidates are other Google web-based applications, for example, Google Sheets (a spreadsheet application), Google Slides (a presentation builder), or the Zoho Office Suite.

\section{Design principles}

Looking back on the development of TOM, three main design principles emerged.

Structure the digital environment around the students' core task.

A learning and performance support system should be organised around the main task or activity of the students. The core component in a digital environment should never overwhelm students in its complexity. One of the risks is that embellishments or scaffolds obscure the students' view (or usage) of the component. In inquiry learning, students must get to know a mathematical or physical model that can be represented well with a simulation. Therefore, a simulation that affords systematic inquiry should be the centrepiece.

In LBD, students must put into practice the knowledge and skills they have learned in class. Therefore, the design process should constitute the core component of the digital environment. Design involves a systematic (stepwise and iterative) process in which understanding the construction problem is followed by prototyping, testing, and revision. The design process (and the individual stages therein) should be easily accessible in the digital environment. In addition, as instructions about the design process had already been given earlier, the emphasis in TOM became that of giving performance support.

In TOM, the usability data provided some evidence in favour of this principle as the Product and Process section received the highest mean overall appraisal compared to the two other sections. Post hoc analyses further revealed a significant difference with the Report section. In addition, the student appraisals for the three usability questions were consistently highest for this design component in TOM (i.e., the ASCE model). In addition, the tools in the Product and Process section received a higher rating as easy to use than the tools in the Report section. The usage data further illustrated that TOM satisfactorily functioned as a performance aid. That is, students used TOM to refresh their memory about what each phase entailed and they closely adhered to the activity checklist provided within each phase. 
Three information types are vital in a learning and performance support system: goals and activities, tools, and background information.

In developing the structural components within the sections of Product and Process, our primary concern was that these should contain only the necessary and sufficient elements. An additional consideration was that each distinct component should be easily recognisable and accessible as such. The distinction between the components of goals and activities, tools, and background information that we developed for TOM was inspired by the four components model, which is widely used for the (systematic) construction of software instructions (van der Meij, Blijleven, \& Jansen, 2003; van der Meij \& Gellevij, 2004).

The goals and activities component describes the design phase and provides students with information about the main activities therein. The goal description serves as a reminder of the main meaning of a phase. In addition, there should be information to "sell" the goal. That is, students may need to be convinced that a particular phase, and the activities therein, requires (more) time and effort than these students may devote otherwise.

The tools component consists of a set of digital applications that support a particular individual or group activity (e.g., brainstorming, group communication, annotation of web pages). Just as elsewhere in TOM, each tool is introduced with a goal description that also includes the "sales argument" of the main functions that it can fulfil (see Figure 2). The inclusion of tools was considered a critical factor for the successful employment of TOM. It made TOM into a rich repository of applications that could alleviate and facilitate the students' actions during design.

The background component provided students with links to pertinent or relevant conceptual information. For instance, in the Analysis section, this component directed students to a website with an overview of instructional design theories to assist them in selecting the proper theory for their intervention. Students were also alerted to the presence of alternative design models to stimulate reflection on the ASCE model.

Time constraints prevented us from properly introducing (and using) the tools in the course parts that preceded the design task. During lectures and in the skills lab, students should have at least become acquainted with the tools that should be used during the design task. In addition, the functionality of TOM would probably have increased when we had provided more scaffolds for the usage of the three components. That is, we should have considered structuring the components in such a way that the students would immediately see the connections between a certain activity, and the available tools and background information for that activity. An additional possibility is that the checklist is not simply an undistinguished list of activities, but one that also ranks or classifies these actions. For instance, the distinction could be made between necessary, optional, and additional activities.

From a theoretical point of view, there is little dispute about the functionality of an information typology for a learning and performance support system. In addition, there is agreement among researchers on the criticality of giving procedural support therein, which led us to include activities and tools. Even so, it would have been desirable to assess whether there was empirical support for this principle. Doing so would, however, have required an analytic effort that was beyond our capabilities within the TOM development efforts.

A learning and performance support environment is preferably all-inclusive.

In setting up TOM, we have held considerable debates around the question of whether or not our learning and performance support environment should be all-inclusive, aiming at providing one platform that offers all the afore-mentioned functionalities under one roof. There were three main reasons for our final choice for inclusiveness:

(1) Students could comfortably exchange information within and across activities, and within and across group members and even classroom participants. The all-inclusiveness probably made the students' task easier, and may also have contributed to their efficiency in completing these.

(2) Presenting the three main sections of Communication, Product and Process, and Report clearly conveyed home the message that these were the main tasks that students were expected to perform in the design task.

(3) The chosen LMS, Moodle, comfortably accommodated the presentation of all these functionalities, resources, and tools in the same environment. Moodle provides an extensive list 
of available plug-ins to integrate various kinds of resources (e.g., uploading documents or linking external resources) and interactive applications (e.g., quizzes or peer feedback), and can be extended by third-party or self-developed applications. Using a browser-based environment, we are following the current trend of using the Internet not only as a means for communications and distribution of resources, but also as a platform for applications to be used in productive and professional contexts. Another aspect of all-inclusiveness is to provide a platform that allows access from various devices (notebook, tablet, smartphone) and from various locations (given an Internet connection), thus building a basis for a flexible and seamless learning and design experience.

The usability data provided tentative support for the decision to make TOM all-inclusive. Much more so than we anticipated, students employed the tools that TOM provided for them in the Communication section. In addition, some students even explicitly expressed their liking that everything they needed to do and have for the design task was possible within the same environment.

In support of the claims for this design principle, we can state that the use of TOM was not obligatory. Students could have worked completely independently from the platform and could have handed in their final report without ever visiting or using TOM. However, the actual usage data (i.e., the platform's activity logs) clearly show the students' acceptance of a platform that offers communication support, productivity tools, and additional information under one roof.

In conclusion, when we started the design of a digital learning and support environment, we paid considerable attention to drawing up the basic requirements and constructing TOM accordingly. There was precious little time for pilot testing with the audience, and partly for this reason, we decided on creating a digital environment that was a rich smorgasbord of options. TOM would benefit from more built-in student support. Above, we discussed the possibility for doing so in connecting the three key information types in the phases of the ASCE model. Preferably, such scaffolding is informed by theory and supported by empirical evidence of its effectiveness (see e.g., McKenney, 2008; Zacharia et al., 2015). Obviously, when more and more scaffolds are being added to an environment, there is a serious risk of too much hand-holding of students. For instance, in real design tasks, students must often prioritise tasks themselves and they themselves must discover which tools are best suited for what activity. Finding the proper balance between support and letting go is one of the major challenges in designing a learning and performance support environment for students. Providing students with just enough information, tools, and scaffolding so that their task remains doable is, of course, also what makes our own design task interesting and challenging.

\section{Limitations and future research opportunities}

Elaborating on the limitations of the presented work, three main aspects emerge: First, the number of participants has been relatively small $(n=35)$, and they originated from a very homogenous study background (second year of the bachelor course "Psychology"). This limits the expressiveness of the presented results - a different picture might develop when repeated with a larger number of students or with students from other disciplines. Secondly, one evaluation method was based on the analysis of student activity logs, but the recorded data may not give always a complete and correct picture: Using the TOM platform solely was not enforced; students could have used other (digital) means of communications and collaboration, and it might have occurred that two or more students were sitting at one computer when using TOM, thus the data might be distorted or not available at all. Thirdly, the design task was pre-structured by the ASCE model for psychological interventions. Although this is a well-established model, and other models are comparable and similar, it still might have an impact on students' behavior and their evaluation of the system.

The limitations particularly question the validity of the design principles we have reached. Further studies are needed to investigate the conditions under which these principles hold. Here, the mentioned limitations can be seen as a starting point to find future research opportunities, for example, future studies should include a larger number of participants from courses which also include design tasks. Also, observing larger sets of students over a longer period of time provides more data as well as more useful data. It may be interesting to test student behaviour and task results with less or more given structure (e.g., structuring the platform along the ASCE model), or allowing students to add interactive and 
collaborative tools themselves (asking them to create parts of their own learning support platform, much in the sense of participatory design practices (Kensing, 2003). This would help to derive more reliable and generalisable conclusions and help to refine the presented design principles.

To conclude, this article presented an approach for the design and deployment of a digital learning and performance support platform for students in the context of LBD group assignments. The described requirements, the ASCE model, and the implementation in the form of an adapted, interactive and collaborative Moodle platform can build a basis for related, similar approaches, while at the same time providing insights and the grounds for further research. As mentioned in the Introduction, the theoretical contribution of this paper is explorative and can help to form new hypotheses and studies in the context at hand. The three design principles which have been elaborated earlier in this section may serve as a practical contribution for the design of similar learning experiences.

\section{References}

Bethke, F. J., Dean, W. M., Kaiser, P. H., Ort, E., \& Pessin, F. H. (1981). Improving the usability of programming publications. IBM Systems Journal, 20(3), 306-320. Retrieved from http://researchweb.watson.ibm.com/journal/sjindex.html

Bollen, L., Eimler, S., Jansen, M., \& Engler, J. (2012). Enabling and evaluating mobile learning scenarios with multiple input channels. In V. Herskovic, H. U. Hoppe, M. Jansen, \& J. Ziegler (Eds.), Collaboration and technology (Vol. 7493, pp. 161-175): Berlin: Springer-Verlag. doi:10.1007/978-3642-33284-5_15

Bransford, J. D., Brown, A. L., \& Cocking, R. R. (2000). How people learn: Brain, mind, experience and school. Washington, DC: National Acadamy Press.

Carlson, M. P., \& Bloom, I. (2005). The cyclic nature of problem solving: An emergent multidimensional problem-solving framework. Educational Studies in Mathematics, 58(1), 45-75. doi:10.1007/s10649005-0808-X

Du Plessis, A., \& Webb, P. (2011). An extended cyberhunts strategy: Learner centered learning-bydesign. Australasian Journal of Educational Technology, 27(7), 1190-1207. Retrieved from http://ajet.org.au/index.php/AJET/article/viewFile/912/189

Edmunds, R., Thorpe, M., \& Conole, G. (2012). Student attitudes towards and use of ICT in course study, work and social activity: a technology acceptance model approach. British Journal of Educational Technology, 43(1), 71-84. doi:10.1111/j.1467-8535.2010.01142.x

Gardner, B. S. (2011). Responsive web design: Enriching the user experience. Sigma Journal: Inside the Digital Ecosystem, 11(1), 13-19.Retrieved from http://www.noblis.org/noblis-media/926e5aba-de4e4927-9884-df6df5d6ce08

Hilbert, D. M., \& Redmiles, D. F. (2000). Extracting usability information from user interface events. ACM Computing Surveys (CSUR), 32(4), 384-421. doi:10.1145/371578.371593

Horn, R. E. (1993). Structured writing at twenty-five. Performance and Instruction, 32(2), 11-17. doi:10.1002/pfi.4170320206

Janssen, F., \& Waarlo, A. J. (2010). Learning biology by designing. Journal of Biology Education, 44(2), 88-92. doi:10.1080/00219266.2010.9656199

Jonassen, D. H. (1997). Instructional design models for well-structured and ill-structured problem-solving learning outcomes. Educational Technology Research and Development, 45(1), 65-94. doi:10.1007/BF02299613

Jonassen, D. H., \& Rohrer-Murphy, L. (1999). Activity theory as a framework for designing constructivist learning environments. Education Technology, Research \& Development, 47(1), 61-79. doi:10.1007/BF02299477

Kensing, F. (2003). Methods and practices in participatory design. Copenhagen: ITU Press.

Khalil, H., \& Ebner, M. (2013, November). Using electronic communication tools in online group activities to develop collaborative learning skills. Paper presented at the 1st International Conference on Open Learning: Role, Challenges, and Aspirations, Kuwait.

Mayer, R. E. (2008). Learning and instruction (2nd ed.). Upper Saddle River, NJ: Pearson.

McKenney, S. (2008). Shaping computer-based support for curriculum developers. Computers \& Education, 50, 248-261. doi:10.1016/j.compedu.2006.05.004

McKenney, S., \& Reeves, T. (2012). Conducting educational design research. London: Routledge.

Polya, G. (1945). How to solve it. Princeton, NJ: Princeton University Press. 
Resnick, L. B. (1987). Learning in school and out. Educational Researcher, 16(9), 13-20. doi:10.3102/0013189X016009013

Romero, C., \& Ventura, S. (2007). Educational data mining: A survey from 1995 to 2005. Expert Systems with Applications, 33(1), 135-146. doi: 10.1016/j.eswa.2006.04.005

Schoenfeld, A. H. (1999). Looking toward the 21st century: Challenges of educational theory and practice. Educational Researcher, 28(7), 4-14. doi:10.3102/0013189X028007004

Schriver, K.A. (1997). Dynamics in document design. New York, NY: Wiley \& Sons.

Spector, J. M., Merrill, M. D., van Merrienboer, J., \& Driscoll, M. P. (Eds.). (2008). Handbook of research on educational communications and technology (3rd ed.). New York: NY: Erlbaum.

van der Meij, H. (2012). E-learning in elementary education. In Z. Yan (Ed.), Encyclopedia of cyber behavior (pp. 1096-1110). Hershey, PA: Information Science Reference.

van der Meij, H., Blijleven, P., \& Jansen, L. (2003). What makes up a procedure? In M. J. Albers \& B. Mazur (Eds.), Content \& complexity: Information design in technical communication (pp. 129-86). Mahwah, NJ: Erlbaum.

van der Meij, H. \& Carroll, J.M. (1998). Principles and heuristics for designing minimalist instruction. In J.M. Carroll (Ed.), Minimalism beyond the Nurnberg funnel (pp. 19-53). Cambridge, MA: MIT Press.

van der Meij, H., \& Gellevij, M. R. M. (2004). The four components of a procedure. IEEE Transactions on Professional Communication, 47(1), 5-14. doi:10.1109/TPC.2004.824292

Vreeman-de Olde, C., de Jong, T., \& Gijlers, H. (2013). Learning by designing instruction in the context of simulation-based inquiry learning. Educational Technology \& Society, 16(4), 47-58. Retrieved from http://www.ifets.info

Wiering, C. H., Pieters, J. M., \& Boer, H. (2011). Intervention design and evaluation in psychology. Enschede: University of Twente, Faculty of Behavioural Sciences.

Wittrock, M. C. (1974). Learning as a generative process. Educational Psychologist, 11(2), 87-95. doi:10.1080/00461527409529129

Zacharia, Z., Manoli, C., Xenofontos, N., de Jong, T., Pedaste, M., van Riesen, S. N., ... Tsourlidaki, E. (2015). Identifying potential types of guidance for supporting student inquiry when using virtual and remote labs in science: A literature review. Educational Technology Research and Development, 63(2), 257-302. doi:10.1007/s11423-015-9370-0

Corresponding author: Lars Bollen, 1.bollen@utwente.nl

Australasian Journal of Educational Technology (C) 2015.

Please cite as: Bollen, L., van der Meij, H., Leemkuil, H., \& McKenney, S. (2015). In search of design principles for developing digital learning \& performance support for a student design task. Australasian Journal of Educational Technology, 31(5), 500-520. 